\title{
A QUANTUM CHEMISTRY APPROACH TO THE ELECTRO- OXIDATION OF CO ADSORBED ON Rh(111) CLUSTER SURFACES*
}

\author{
P. PAREDES OLIVERA, G.L. ESTIÚ, E.A. CASTRO and A.J. ARVÍA \\ Instituto de Investigaciones Fisicoquimicas Teoricas y Aplicadas (INIFTA), \\ Facultad de Ciencias Exactas, Universidad Nacional de la Plata, Casilla de Correo 16, \\ Sucursal 4, (1900) La Plata (Argentina)
}

\section{ABSTRACT}

A molecular-orbital interpretation of the electro-oxidation of $\mathrm{CO}$ adsorbed on $\mathrm{Rh}$ (111) singlecrystal clusters in the presence of $\mathrm{H}_{2} \mathrm{O}$ is described. Calculations were based on the atom superposition and electron delocalization method. Different stabilization energies for ensembles of the type $[\mathrm{Me}]_{N}(\mathrm{CO})_{n}(\mathrm{OH})_{m}$ for $\mathrm{Me}=\mathrm{Rh}$ or $\mathrm{Pt}$ are given. The stability of possible $\mathrm{CO}$ adsorbate configurations on $\mathrm{Rh}(111)$ surfaces depends on the applied electric potential in a way which is directly comparable with the one reported previously for $\mathrm{CO}$ adsorbates on $\mathrm{Pt}(111)$. Only linearly bonded $\mathrm{CO}$ adsorbates appear to be involved in the electrochemical $\mathrm{CO}$ oxidative interaction with $\mathrm{H}_{2} \mathrm{O}$ molecules on both $\mathrm{Rh}(111)$ and $\mathrm{Pt}(111)$.

\section{INTRODUCTION}

The electronic and molecular structure of the electrochemical interface plays a decisive role in determining the kinetics and the mechanism of processes that occur at electrocatalytic solid surfaces. This matter has been of particular interest in the last decade and it has stimulated the application of surface physico-chemical techniques, either in situ or ex situ, to establish the possible adsorbate structures at the electrochemical interface [1-6]. These studies have recently provided valuable information from the examination of synthetic interfaces $[7,8]$ built up by means of the co-adsorption of carefully selected adsorbates capable of simulating the structure of the adsorbed layer and the effective electrode potential simultaneously.

Co-adsorption studies such as those involving the electro-oxidation of $\mathrm{CO}$ adsorbates in acid solution, either hydrophilic on $\mathrm{Rh}(111)$ or hydrophobic on $\mathrm{Pt}$ (111) electrodes [9], have shown that the corresponding reactants could be described as complex adsorbates resulting from cooperative interactions be-

\footnotetext{
*Presented at the 18th International Congress of Theoretical Chemists of Latin Expression, held at La Plata, Argentina. 23-28 September, 1989.
} 
tween different species at the electrochemical interface [10,11]. The influence of $(\mathrm{CO})_{\mathrm{ad}}(\mathrm{OH})_{\mathrm{ad}}$ lateral interactions on $\mathrm{CO}$ adsorbate electro-oxidation kinetics on Pt(111) has been recently semiempirically evaluated [12] in terms of the stability of the different adsorbate ensembles represented by the general stoichiometry $[\mathrm{Pt}]_{N}(\mathrm{CO})_{n}(\mathrm{OH})_{m}$. In this case the $\mathrm{OH}$ co-adsorbate which results from the direct electro-oxidation of $\mathrm{H}_{2} \mathrm{O}$ at $0.6 \mathrm{~V}$ (vs. $\mathrm{RHE}$ ) favours that complex adsorbate structure. The stability of those ensembles depends on the value of $n$ and $m$, and on the applied electric potential. Therefore, it is reasonable to expect that the voltammetric electro-oxidation of $\mathrm{CO}$ adsorbed on $\mathrm{Pt}$ gives rise to distinguishable electro-oxidation peaks for different $\mathrm{CO}$ coverages, as each $m / n$ stoichiometric ratio should be related to a well-defined limit of the stability of the adsorbate ensemble.

In contrast to previous kinetic interpretations which concluded that the position of $\mathrm{CO}$ electro-oxidation voltammetric current peaks should be assigned to different $\mathrm{CO}$ coordination geometries on $\mathrm{Pt}$, i.e. linearly bonded, bridged and multiply bonded adsorbed CO states, the molecular-orbital (MO) calculations allow it to be concluded that the multiplicity and location of the voltammetric peaks could be reasonably explained through cooperative interactions among preadsorbed $\mathrm{OH}$ species and a different number of linearly bonded adsorbed $\mathrm{CO}$ molecules on Pt.

The electro-oxidation of $\mathrm{CO}$ adsorbed on $\mathrm{Rh}$ in acid solutions has been often compared with the reaction occurring on $\mathrm{Pt}[9,13]$. Accordingly, the kinetics of the reaction on $\mathrm{Rh}$ has been explained in terms of two distinguishable $\mathrm{CO}$ adsorbates, but, in this case, the appearance of a single voltammetric current peak was explained through the interconversion of adsorbed $\mathrm{CO}$ from bridge to linear coordination, a process which on $\mathrm{Rh}$ was faster than on $\mathrm{Pt}$ [13]. In contrast, the binding energies (BE) derived from MO calculations for the electric potential related to $\mathrm{CO}$ electro-oxidation, indicate that the linear $\mathrm{CO}$ adsorbate configuration on $\mathrm{Rh}$ becomes sufficiently stable [14], turning out to the spontaneous change from linear to bridged $\mathrm{CO}$ adsorbate rather unlikely. However, the location of the $\mathrm{CO}$ adsorbate electro-oxidation peak on $\mathrm{Rh}$ is highly dependent on the electrolyte solution composition $[13,15,16,28,29]$. The $\mathrm{CO}$ adsorbate electro-oxidation voltammetric peak on $\mathrm{Rh}$ in acid media (1 M $\mathrm{HClO}_{4}, 0.5 \mathrm{M} \mathrm{H}_{2} \mathrm{SO}_{4}$ ) appears at about $0.75 \mathrm{~V}[15,16]$, whereas in neutral 0.2 $\mathrm{M} \mathrm{K}_{2} \mathrm{SO}_{4}$ it is found at $0.95 \mathrm{~V}$. However, a single voltammetric peak at $0.95 \mathrm{~V}$ was recorded in $1.0 \mathrm{M} \mathrm{HClO}_{4}$ after the $\mathrm{CO}$ monolayer surface coverage had been attained [13].

This paper is devoted to a MO-based description of $\mathrm{CO}$ adsorbate electrooxidation on $\mathrm{Rh}(111)$ in the presence of $\mathrm{H}_{2} \mathrm{O}$. The results can be used to interpret the corresponding electrochemical data available at present in the literature $[13,15,16]$. The calculation procedure, which has been described in an earlier publication [14], is based on the existence of strong lateral interactions between $\mathrm{CO}$ and $\mathrm{H}_{2} \mathrm{O}, \mathrm{CO}$ and $\mathrm{OH}$, and $\mathrm{COH}$ and $\mathrm{OH}$ co-adsorbates on $\mathrm{Rh}$ (111) 
clusters under different applied electric potentials. Both $\mathrm{H}_{2} \mathrm{O}$ and $\mathrm{CO}$ form a stable co-adsorbate on $\mathrm{Rh}(111)$ already at $0.0 \mathrm{~V}$ vs. the reversible hydrogen electrode (RHE). Then, both the $\mathrm{H}_{2} \mathrm{O}-\mathrm{CO}$ or $\mathrm{CO}-\mathrm{OH}$ lateral interactions extend over the entire potential range where bulk $\mathrm{H}_{2} \mathrm{O}$ becomes thermodynamically stable $[9,14]$. The characteristics of these interactions change considerably with both the applied electric potential and the solution composition.

\section{OUTLINE OF THE CALCULATION PROCEDURE}

In a previous paper [14] atom-superposition and electron-delocalization (ASED-MO) calculations [17,18] were employed for modelling the CO-adsorbate configurations on a $\mathrm{Rh}(111)$ cluster surface as a function of the applied electric potential. The same procedure was employed in the present study to describe the changes in the $\mathrm{CO}-\mathrm{H}_{2} \mathrm{O}$ adsorbate structure on $\mathrm{Rh}(111)$ as the applied electric potential is set increasingly positive to reach the region where the $\mathrm{CO}$ electro-oxidation reaction begins.

The $R h(111)$ surface was built up from [Rh $]_{22}$ high-spin bulk superimposable clusters as described in Ref. 14 for the same geometric parameters (Fig. 1 ). This is the smallest cluster dimension which minimizes border effects when cooperative interactions between adsorbates on the central four-atom-cluster region are considered (Fig. 2). The parameters which define the uncharged $[\mathrm{Rh}(111)]_{22}\left(\mathrm{H}_{2} \mathrm{O}\right)_{m}(\mathrm{CO})_{n}$ adsorbed ensemble were taken from Ref. 14 and, due to the invariance of $\mathrm{Rh}-\mathrm{O}$ charge transfer on the metal surface, these parameters remained unchanged when adsorbed $\mathrm{H}_{2} \mathrm{O}$ was replaced by $\mathrm{OH}$ adsorbate (Table 1 ).

Both $\mathrm{CO}[11,12,23]$ and $\mathrm{OH}[11,24]$ species adsorb in a linear configuration perpendicular to the metal surface. The $\mathrm{C}-\mathrm{O}$ and $\mathrm{O}-\mathrm{H}$ interatomic distances were fixed at 1.16 and $1.00 \AA$, respectively. The $\mathrm{OH}$ adsorbate is located 1.95 $\AA$ from the $\mathrm{Rh}$ (111) surface and $2.0 \AA$ from the $\mathrm{Pt}$ (111) surface, whereas the $\mathrm{CO}$ adsorption distances were 1.95 for $\mathrm{Rh}(111)$ and $2.00 \AA$ for $\operatorname{Pt}(111)$. The

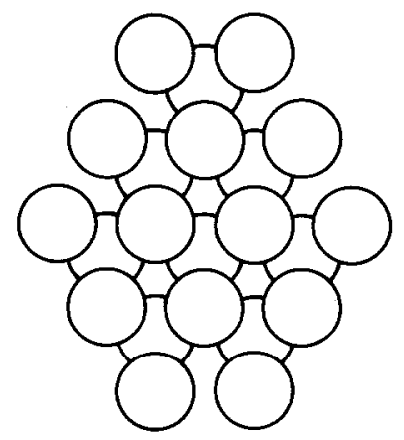

Fig. 1. Cluster used to model the $[R h(111)]_{22}$ surface structure. 

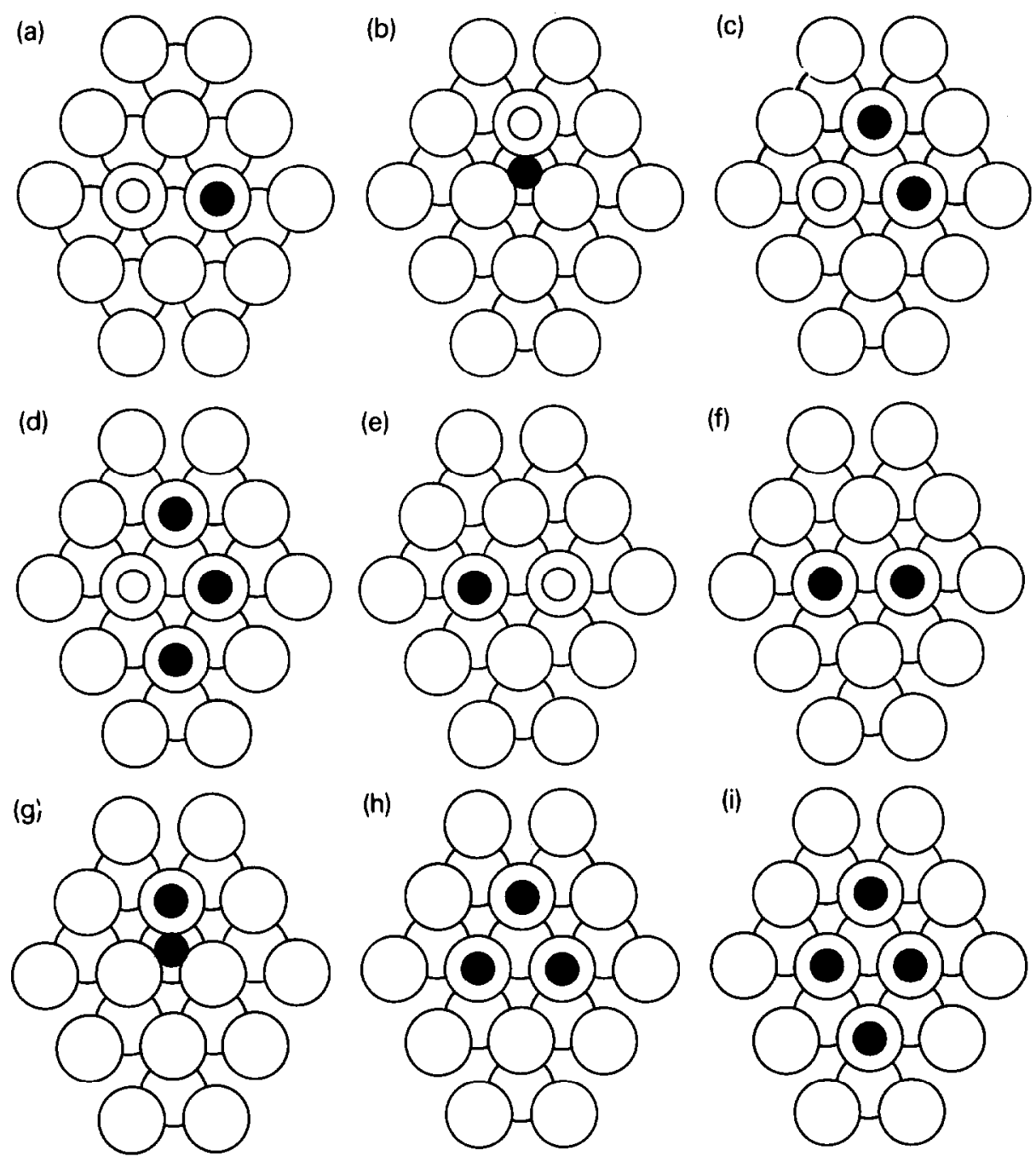

Fig. 2. Local structures involving the central atoms of the cluster. The energy of the various configurations are compared in order to define the stability inversion potential (SIP) on Rh(111). Comparisons are of structures a and $\mathrm{f}, \mathrm{b}$ and $\mathrm{g}, \mathrm{c}$ and $\mathrm{h}, \mathrm{d}$ and $\mathrm{g}$, and $\mathrm{e}$ and $\mathrm{f}$. (O) $\mathrm{OH}$; (O) CO; (O) $\mathrm{COH}$ (in Fig. 2 (e)).

metal- $\mathrm{O}$ bonding for $\mathrm{OH}$ adsorption implies an ionic character (charge transfer). The adsorption bond lengths were calculated from the corresponding minimum energy value. They are directly related to the sum of the corresponding atomic radii. In contrast to the fact that covalent radii are almost the same for $\mathrm{Rh}$ and $\mathrm{Pt}$, the ionic radii for $\mathrm{Rh}$ is $65 \%$ larger than that for $\mathrm{Pt}$. This difference is reflected in the $\mathrm{C}$-metal adsorption bond length which, in the presence of co-adsorbed $\mathrm{OH}$, is $0.19 \AA \mathrm{A}$ longer for Rh than for Pt. This means that 


\section{TABLE 1}

Parameters used in the calculations: principal quantum number $(n)$, orbital exponents $(\xi)$, ionization potential (VSIP) and the corresponding coefficients $\left(C_{1}\right.$ and $\left.C_{2}\right)$ for $d$ orbitals

\begin{tabular}{|c|c|c|c|c|c|c|c|}
\hline \multirow[t]{2}{*}{ Atom $^{a}$} & & \multicolumn{3}{|l|}{$s$} & \multicolumn{3}{|l|}{$p$} \\
\hline & & $n$ & $\xi$ & VSIP & $n$ & $\xi$ & VSIP \\
\hline \multirow[t]{2}{*}{0} & (A) & 2 & 1.946 & -26.98 & 2 & 1.927 & -12.12 \\
\hline & (B) & 2 & 2.146 & -26.98 & 2 & 2.127 & -12.12 \\
\hline $\mathbf{H}$ & (A) & 1 & 1.000 & -12.10 & & & \\
\hline $\mathrm{C}$ & (B) & 2 & 1.658 & -18.50 & 2 & 1.618 & -9.760 \\
\hline \multirow[t]{3}{*}{$\mathrm{Rh}$} & (C) & 5 & 2.135 & -9.670 & 5 & 2.100 & -6.314 \\
\hline & & \multicolumn{6}{|l|}{$d$} \\
\hline & & $n$ & $\xi_{1}$ & VSIP & $C_{1}$ & $C_{2}$ & $\xi_{2}$ \\
\hline $\mathrm{Rh}$ & (C) & 4 & 4.290 & -11.77 & 0.5807 & 0.5685 & 1.970 \\
\hline
\end{tabular}

(A) Atom in $\mathrm{H}_{2} \mathrm{O}$ molecule; (B) atom in $\mathrm{CO}$ molecule; (C) $\mathrm{Rh}$ in the $[\mathrm{Rh}(111)]_{19}(\mathrm{OH})_{n}(\mathrm{CO})_{m}$ system.

for the co-adsorbed ensemble the $\mathrm{Rh}-\mathrm{C}$ bond length increases from 1.95 to 2.24 Å.

In order to simulate positive applied electric potentials (positive charging) valence state ionization potential (VSIP) values were decreased (increased in absolute value) from those which define the zero potential condition. In previous studies related to $\mathrm{CO}$ adsorbates on $\mathrm{Rh}(111)$ [14] changes of $\pm 1.0 \mathrm{eV}$ in VSIP have been correlated to changes of $\pm 1.0 \mathrm{~V}$ from the zero potential. In this way the correct trend in the $\mathrm{CO}$ adsorption-geometry change with the applied electric potential was accomplished. When the $\mathrm{CO}$ electro-oxidation on $\mathrm{Pt}(111)$ was considered [12], a $1.0 \mathrm{~V}$ shift in the applied potential was correlated to a $0.32 \mathrm{eV}$ shift in the corresponding Fermi energy level. This energy-scale adjustment gave very good agreement between the position of the various $\mathrm{CO}$ voltammetric electro-oxidation peaks on $\mathrm{Pt}$ in acid and the stabilization energies of the different $\mathrm{Pt}(\mathrm{CO}) \cdot \mathrm{Pt}(\mathrm{OH})$ adsorbate ensembles. A similar correlation emerged for the $\mathrm{CO}$ voltammetric electro-oxidation peaks on $\mathrm{Rh}(111)$ provided that the energy scale (linear work function vs. applied electric potential correlation) is adjusted to $0.3 \mathrm{eV} \mathrm{V}^{-1}$. The fact that the behaviour of $\mathrm{CO}$ adsorbates on $\mathrm{Pt}(111)$ and $\mathrm{Rh}(111)$ is similar indicates that both types of adsorbate "feel" about $30 \%$ of the entire potential drop applied to the metal/solution interface, in agreement with the experimental findings for the CO-Pt(111) interface [19].

It should be noted that the one-to-one correlation between the work function in an electrochemical environment and the applied electric potential, derived 
from ESCA data for Au electrodes immersed in a cesium halide containing solution $[1,20]$, has been extended to interpret data of other systems $[14,21]$. In contrast, the shift in Fermi energy level with the applied electric potential differs appreciably for various metal/electrolyte interfaces, as expected, because the characteristics of this correlation is determined by both surface and bulk state energies, which in turn exhibit specific responses to the applied electric potential. A $0.3-\mathrm{eV}$ shift in surface state energy was measured for a $1.0-\mathrm{V}$ shift in the energy of bulk states for the $\mathrm{Au}(100) / 0.5 \mathrm{M} \mathrm{NaF}$ system, whereas slopes ranging between 3 and $4 \mathrm{eV} / \mathrm{V}$ were observed for the $\mathrm{Ag}(110) / 0.5 \mathrm{M}$ NaF interface [22].

The influence of surface-state concentration on the adsorbate behaviour at solid electrode surfaces explains the $0.3 \mathrm{eV} \mathrm{V}^{-1}$ slope for the correlation between the $\mathrm{CO}$ electro-oxidation peak potentials (in volt) and the stability energy of the $\mathrm{Rh}(\mathrm{CO}) \cdot \mathrm{Rh}(\mathrm{OH})$ co-adsorbates (in $\mathrm{eV}$ ) calculated for different Fermi level energy values.

\section{RESULTS AND INTERPRETATION}

\section{Structural aspects}

For a molecular-level interpretation of the present results and for establishing a correlation between theory and experimental data it is convenient to consider the results obtained previously for $\mathrm{Pt}(111)$ [12]. The interpretation of $\mathrm{CO}$ adsorbate electro-oxidation voltammetric data on $\mathrm{Rh}$ and $\mathrm{Pt}$ electrodes in acids has been based upon the same type of interactions [13], despite the fact that the reaction exhibits two voltammetric current peaks on Pt [15,25,27], but a single peak on $\mathrm{Rh}[13,14,28,29]$, the location of the latter being dependent on the electrolyte composition and $\mathrm{pH}$ [16].

The appearance of a single voltammetric peak for the adsorbate electrooxidation on $\mathrm{Rh}$ has been explained through an energy difference of the linear and bridge $\mathrm{CO}$ adsorbates on $\mathrm{Rh}$ smaller than that resulting for the same species on $\mathrm{Pt}$, i.e. the interconversion from "bridge" to "linear" CO adsorbate on $\mathrm{Rh}$ becomes considerably more facile [13] than on $\mathrm{Pt}$. However, this interpretation can hardly be supported through MO calculations [14], as in this case a similar BE difference between bridged and linearly bonded $\mathrm{CO}$ on both $\mathrm{Pt}(111)$ and $\mathrm{Rh}(111)$ surfaces is obtained. However, it should be noted that the interconversion mechanism offers no explanation for the $\mathrm{pH}$ dependence of the $\mathrm{CO}$ adsorbate electro-oxidation peak potential on $\mathrm{Rh}$. It was found that $\mathrm{CO}$ displaces $\mathrm{H}$ adatoms from $\mathrm{Rh}$ with great difficulty $[13,30]$, so that a complete CO monolayer in acid solutions can hardly be obtained. Nevertheless, after a prolonged adsorption time the $\mathrm{CO}$ adsorbate electro-oxidation voltammogram on $\mathrm{Rh}$ becomes independent of the solution $\mathrm{pH}$ [13]. Furthermore, in contrast to the interconversion mechanism, the $\mathrm{MO}$ calculation indicates that 
the $\mathrm{H}$ adatom concentration remaining on the $\mathrm{Rh}$ surface after $\mathrm{CO}$ adsorbate formation determines the location of the $\mathrm{CO}$ electro-oxidation peaks through their occupancy of surface sites.

As it has been previously reported for $\mathrm{Pt}(111)$ [12], CO adsorbate electrooxidation on $\mathrm{Rh}(111)$ can be also described through the stability of the different $[\mathrm{Rh}(111)]_{22}(\mathrm{CO})_{n}(\mathrm{OH})_{m}$ ensembles on the basis of possible stages participating in the $\mathrm{CO}$ adsorbate electro-oxidation [27]. This sequence of stages can be compared more critically with the interconversion mechanism derived from voltammetry data, by considering the influence of the applied electric potential on the stability of the different adsorbate ensembles.

In addition to the $[\mathrm{Rh}(111)]_{22}(\mathrm{OH})(\mathrm{CO})$ and $[\mathrm{Rh}(111)]_{22}\left(\mathrm{H}_{2} \mathrm{O}\right)(\mathrm{CO})$ ensembles formed on the $\mathrm{Rh}(111)$ uncharged surface [14], other configurations such as the $[\mathrm{Rh}(111)]_{22}(\mathrm{COH})(\mathrm{OH})$ one, which may result from a chemical reaction at the surface level can also be considered. For a certain applied electric potential, oxidative interactions yielding $\mathrm{CO}_{2}$ as product leave a $[\mathrm{Rh}(111)]_{22}(\mathrm{CO})_{n+m}$ ensemble, the formation of which becomes more favourable than that of the $\mathrm{CO}-\mathrm{OH}, \mathrm{CO}-\mathrm{H}_{2} \mathrm{O}$ or the $\mathrm{COH}-\mathrm{OH}$ co-adsorbed structure $[12,28]$.

Although the true structure of the $\mathrm{Rh}(111) /$ electrolyte solution interface in the presence of $\mathrm{CO}$ adsorbates cannot be described exactly, a reasonable picture of the adsorbate structures resulting for different $\mathrm{CO}$ surface coverages can be envisaged from the $\mathrm{Rh} / \mathrm{CO}$ (gas) interface spectroscopic data [30-32]. Thus, at low CO surface coverages, a $(\sqrt{3} \times \sqrt{3}) R 30^{\circ}$ LEED pattern is produced through the $\mathrm{CO}$ occupancy of $\mathrm{Rh}(111)$ top sites (Fig. 3). This structure gives rise to the $\mathrm{CO} \cdot \mathrm{OH}$ interactions depicted in Fig. 2(a). Otherwise, at high CO surface coverages, the simultaneous occupancy of $\mathrm{Rh}(111)$, top and hollow sites results in a $c(2 \times 2)$ LEED pattern (Fig. 4). The possible interactions between the co-adsorbed $\mathrm{CO}$ and $\mathrm{OH}$ species in this case are illustrated in Figs. 2(a-c). The structure depicted in Fig. 2(c) is formed under a positive applied

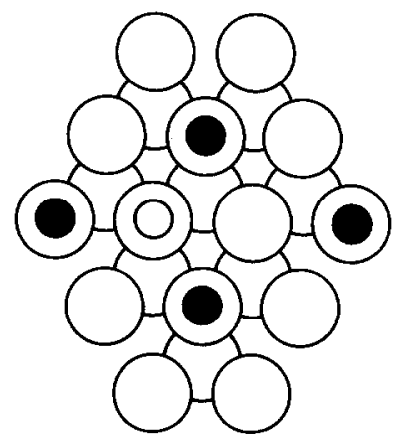

Fig. 3. The $(\sqrt{3} \times \sqrt{3}) R 30^{\circ} \mathrm{LEED}$ pattern corresponding to $\mathrm{CO}$ adsorbed on $\mathrm{Rh}(111)$ for $\theta=0.33^{\circ}$ [31]. The possible $\mathrm{OH}$ adsorption site is also included. The structure of the adsorbed layer remains on the application of a positive potential. 

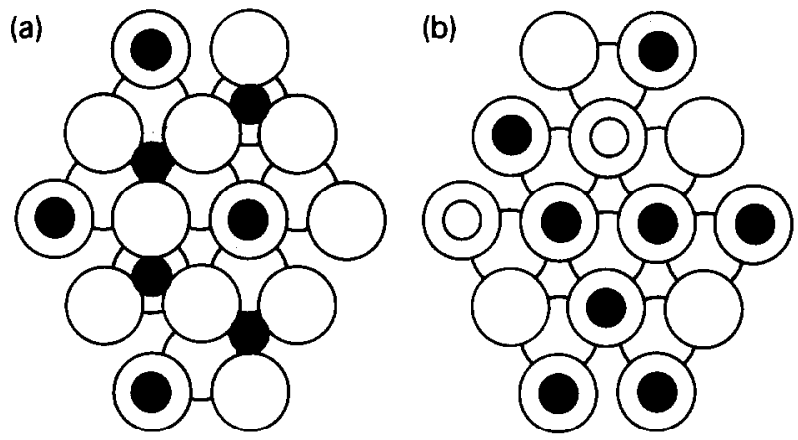

Fig. 4. (a) Adsorbed structure as derived from the $c(2 \times 2)$ LEED pattern of $C O$ adsorbed on the $\mathrm{Rh}$ (111) uncharged surface for $\theta=0.5^{\circ}[31,32]$. The $\mathrm{OH}$ adsorption site is also included. (b) Adsorbed structures resulting from the application of a positive potential to the initial $c(2 \times 2)$ structure. $\mathrm{CO} ; \mathrm{O}, \mathrm{OH}$.

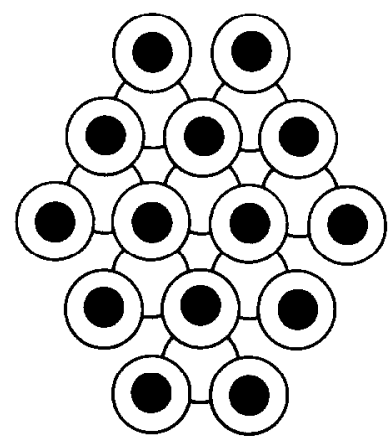

Fig. 5. Adsorbed structure for $\theta=1.0^{\circ}$ and a positive applied potential. A local (CO $)_{\text {ad }}$ vacancy is necessary for $\mathrm{OH}$ adsorption. $\mathrm{CO}$.

electric potential (positive charging) which assists the shift of the $\mathrm{CO}$ adsorbate from a highly to singly coordinated $\mathrm{Rh}(111)$ site [14]. Unfortunately, there is no information concerning adsorbate structures at higher $\mathrm{CO}$ surface coverages on the $\mathrm{Rh} / \mathrm{CO}$ (gas) interface, although calculations show that for positive applied electric potentials, an adsorbate structure such as that depicted in Fig. 5, could be obtained through the type of interaction depicted in Fig. 2(d). However, the $\mathrm{CO}-\mathrm{H}_{2} \mathrm{O}$ coadsorbate may also undergo a chemical reaction yielding the $\mathrm{COH} \cdot \mathrm{OH}$ structure shown in Fig. $2(\mathrm{e})$.

The energy of the co-adsorbed structures represented in Figs. 2(a)-(e) changes continuously as the potential increases from 0.0 to $1.0 \mathrm{~V}$, and becomes gradually more labile than those depicted in Figs. 2(f)-2(i). Hence, on the basis of these results, it is possible to define a stability inversion potential (SIP) at which the structure containing two different interacting near-neighbour adsorbate units, either $\mathrm{CO}-\mathrm{OH}$ or $\mathrm{COH}-\mathrm{OH}$, change into a new adsorbate structure built up by means of adsorbed $\mathrm{CO}$, and leading to $\mathrm{CO}_{2}$ production. 
The SIP values related to the different adsorbate configurations can be correlated directly with the potentials of the various voltammetric peaks for the electro-oxidation to $\mathrm{CO}_{2}$ of $\mathrm{CO}$ adsorbed on $\mathrm{Rh}(111)$ in aqueous solution $[13,15,16]$. Thus, according to data assembled in Table 2 the voltammetric peak at $0.95 \mathrm{~V}$ can be assigned to the electro-oxidation threshold potential for the rupture of the $(\mathrm{CO})_{3}(\mathrm{OH})$ adsorbate ensemble (Fig. 2(d)). The $(\mathrm{CO})_{3}(\mathrm{OH})$ ensemble should be produced at $\mathrm{CO}$ surface coverages approaching the monolayer value. It should be noted that in this case the electro-oxidation voltammogram shows a shoulder at $0.75 \mathrm{~V}$ appearing together with the peak at $0.95 \mathrm{~V}$ [13]. On the basis that $\mathrm{CO}$ hardly displaces $\mathrm{H}$ adatoms from the $\mathrm{Rh}$ surface, it sounds reasonably that under these circumstances in acid solutions, co-adsorbate interactions such as those depicted in Fig. 2(c) are involved, as the fourth adsorption site on $\mathrm{Rh}(111)$ is then occupied by a $\mathrm{H}$ atom. Accordingly, depending on the solution $\mathrm{pH}$, the voltammetric electrooxidation peak of $\mathrm{CO}$ adsorbates on $\mathrm{Rh}(111)$ for a relatively prolonged adsorption time would appear at either 0.95 or $0.75 \mathrm{~V}$.

Otherwise, for low $\mathrm{CO}$ surface coverage and linear $\mathrm{CO}$ adsorbate coordination assisted through a positive charging, the rupture of the resulting $(\mathrm{CO})_{2}(\mathrm{OH})$ ensemble (Fig. $2(\mathrm{c})$ ) would give rise to the electro-oxidation peak at $0.75 \mathrm{~V}$. The latter can be also seen for high $\mathrm{CO}$ surface coverages in acid electrolyte solutions.

The $\mathrm{CO}-\mathrm{OH}$ interactions resulting for the structure depicted in Fig. 2(a), prevailing at low CO surface coverages, would produce a voltammetric electro-

\section{TABLE 2}

Correlation between SIP values (expressed as $\mathrm{H}_{585 s \mathrm{Rh}}$ ) and the voltammetric peak potentials related to the electro-oxidation of different $\mathrm{CO}$ adsorbates on $\mathrm{Rh}(111)^{\mathrm{a}}$

\begin{tabular}{|c|c|c|c|}
\hline Adsorbate on $[\mathrm{Rh}(111)]_{22}$ & $\begin{array}{l}\text { Elcctro-oxidation } \\
\text { potential (V) }\end{array}$ & $\begin{array}{l}\text { SIPb }^{\mathbf{b}} \\
(\mathrm{eV})\end{array}$ & $\begin{array}{l}\mathrm{CBE}^{\mathrm{c}} \\
(\mathrm{eV})\end{array}$ \\
\hline $\begin{array}{l}(\mathrm{CO})(\mathrm{OH}) /(\mathrm{CO})_{2} \\
\text { Fig. } 2(\mathrm{a}) \text { and } 2(\mathrm{f})\end{array}$ & 0.47 & -9.81 & 7.36 \\
\hline $\begin{array}{l}(\mathrm{CO})_{2}(\mathrm{OH}) /(\mathrm{CO})_{3} \\
\text { Fig. } 2(\mathrm{~b}) \text { and } 2(\mathrm{~g})\end{array}$ & 0.75 & -9.89 & 5.48 \\
\hline $\begin{array}{c}(\mathrm{CO})_{3}(\mathrm{OH}) /(\mathrm{CO})_{4} \\
\text { Fig. } 2(\mathrm{c}) \text { and } 2(\mathrm{~h})\end{array}$ & 0.95 & -9.95 & 3.66 \\
\hline $\begin{array}{l}(\mathrm{CO})^{\mathrm{H}}(\mathrm{OH})^{\mathrm{T}} /(\mathrm{CO})^{\mathrm{H}}(\mathrm{CO})^{\mathrm{T}} \\
\text { Fig. } 2(\mathrm{~d}) \text { and } 2(\mathrm{i})\end{array}$ & 1.62 & -10.15 & 3.14 \\
\hline
\end{tabular}

The values given in the table indicate the possible adsorbed structures which give rise to the voltammetric CO electro-oxidation peaks on $\mathrm{Rh}$ in aqueous solutions when the $0.3 \mathrm{eV} \mathrm{V}^{-1}$ correlation is used. 'SIP are expressed as ionization-potential values of the $\mathrm{Rh}(111)$ surface, i.e. the way in which electrode charging was simulated. ${ }^{\circ} \mathrm{Co}$-adsorption $\mathrm{BE}$ (CBE) values calculated at the SIP value of each structure: $\left.\mathrm{CBE}=E_{\left[\mathrm{Rh}(111)_{22}(\mathrm{CO})_{n}(\mathrm{OH})_{m}\right.}-E_{[\mathrm{Rh}(111)]_{22}}-n E_{\mathrm{CO}}-m E_{\mathrm{OH}}\right)$. 
oxidation peak at $0.47 \mathrm{~V}$, which would be observed on $\mathrm{Rh}(111)$ at low $\mathrm{CO}$ surface coverage. This peak has not been observed experimentally. Nevertheless, providing that in this case the influence of the applied electric potential on the adsorbate structure becomes sufficiently small, the $(\mathrm{CO})(\mathrm{OH}) \mathrm{co}$-adsorbate can originate several new configurations such as those depicted in Fig. 2(b), which in turn become less stable than that shown in Fig. 2 (g). Likewise, sufficiently large positive charging can change the adsorbate structure from that shown in Fig. 2(b) into that illustrated in Fig. 2(a).

The co-adsorption of $\mathrm{H}_{2} \mathrm{O}$ and $\mathrm{CO}$ on $\mathrm{Rh}(111)$ at zero potential can also produce the structure depicted in Fig. 2 (e) through a surface reaccommodation reaction [9]. The resulting unstable adsorbate would also be electro-oxidized at a relatively low potential, which in this case is in the potential range of the hydrogen evolution reaction. In this case the unstable $(\mathrm{OH})_{\text {ad }}$ species on $\mathrm{Rh}$ (111) would result exclusively from a surface chemical reaction. Nevertheless, all these unstable structures, which have only been deduced theoretically, are excluded from Table 2.

\section{Molecular orbital interpretation}

Cooperative interactions resulting from co-adsorbed $\mathrm{CO}$ and $\mathrm{OH}$ on $\mathrm{Rh}(111)$ can be described in the basis of $\mathrm{MO}$ interactions involving $\mathrm{CO}$ and $\mathrm{OH}$ adsorption on transition-metal surfaces $[12,23,24]$. It should be noted that $\mathrm{H}_{2} \mathrm{O}$ electrodecomposition yielding adsorbed $\mathrm{OH}$ and $\mathrm{H}^{+}$ions on $\mathrm{Rh}$ in acid solution begins at a potential at which the $\mathrm{Rh}(111)$ surface is already mostly covered by linearly bonded $\mathrm{CO}$ adsorbate.

The stabilization of $\mathrm{OH}$ orbitals through bonding interactions occurs similarly on both the $[\mathrm{Rh}(111)]_{22}(\mathrm{CO})_{n}$ and $[\mathrm{Rh}(111)]_{22}$ substrates. However, perturbative interactions involving $\mathrm{OH}$ and preadsorbed $\mathrm{CO}$ increase the energy of the antibonding $\mathrm{Rh}(\mathrm{OH})$ orbital levels, a fact which explains why $\mathrm{OH}$ becomes more strongly bonded to the metal as $n$, the number of $\mathrm{CO}$ molecules in the adsorbate ensemble, increases. Thus, for a given applied electric potential and metal surface structure (Fig. 6), a comparison of the adsorptive stabilization energies for $\mathrm{OH}$ on $[\mathrm{Rh}(111)]_{22}, \quad[\mathrm{Rh}(111)]_{22}(\mathrm{CO})$, $[\mathrm{Rh}(111)]_{22}(\mathrm{CO})_{2}$ and $[\mathrm{Rh}(111)]_{22}(\mathrm{CO})_{3}$ indicates an increasing stability of the co-adsorbate ensemble produced by the less effective $\mathrm{OH}$ antibonding interaction.

However, the Fermi energy level of Rh decreases with positive applied electric potentials (positive charging). Accordingly, the stability of co-adsorbate ensembles decreases on increasing the strength of the antibonding interactions, leading to their desorption as $\mathrm{CO}_{2}$ and $\mathrm{H}^{+}$in solution when the corresponding threshold potential value is reached. Therefore, a definite threshold potential value can be associated with the electro-oxidation-desorption condition of each particular adsorbate ensemble on the $\mathrm{Rh}(111)$ substrates. The 


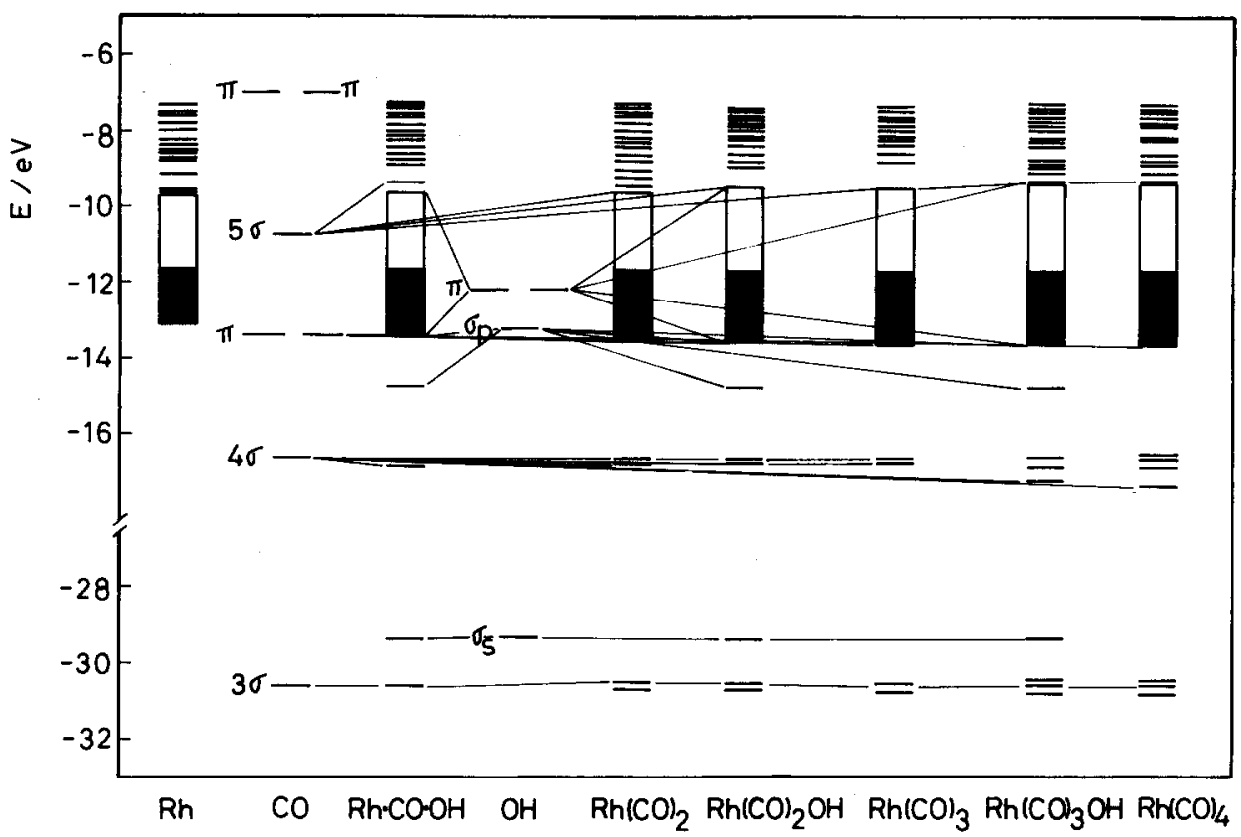

Fig. 6. Molecular-orbital correlation diagrams for the adsorption of $(\mathrm{CO})_{n}(0 \leqslant n \leqslant 3)$ and $(\mathrm{OH})$ on $\operatorname{Rh}(111)$.

greater the $\mathrm{CO}$ surface coverage the higher the applied electric potential required for the adsorbate electro-oxidative desorption.

\section{CONCLUSIONS}

Semiempirical ASED-MO calculations provide the basis for a structural interpretation of adsorbed CO electro-oxidation reaction on $\mathrm{Rh}(111)$ singlecrystal clusters in the presence of $\mathrm{H}_{2} \mathrm{O}$.

The appearance of a single voltammetric electro-oxidation peak, which is observed after a sufficiently prolonged $\mathrm{CO}$ adsorption time, that is, for a $\mathrm{Rh}$ surface nearly completely covered by $\mathrm{CO}$, has been explained through the facile interconversion of multiply bonded $\mathrm{CO}$ adsorbates into linearly bonded ones on the Rh surface $[13,18]$. The peak position depends on electrolyte composition $[13,15,16]$.

According to the present $\mathrm{MO}$ calculations, the single electro-oxidation peak at $0.95 \mathrm{~V}$ resulting for $\mathrm{Rh}(111)$ obtained in neutral solutions when the monolayer $\mathrm{CO}$ surface coverage has been closely attained, results from cooperative interactions involving $\mathrm{OH}$ species co-adsorbed with a relatively large number of linearly bonded $\mathrm{CO}$ molecules.

As the $\mathrm{Rh}$ surface sites begin to be occupied by $\mathrm{H}$ adatoms in acid electrolytes 
$[15,16]$, the complete $\mathrm{CO}$ surface coverage monolayer cannot be achieved, resulting in the displacement of the $\mathrm{CO}$ electro-oxidation peak to a lower potential $(0.75 \mathrm{~V})$. Therefore, under controlled $\mathrm{CO}$ exposure time and adsorption potential conditions, it is possible to observe, also in acid solutions, the main $\mathrm{CO}$ electro-oxidation voltammetric peak on $\mathrm{Rh}(111)$ expected at $0.95 \mathrm{~V}$ accompanied by a shoulder at $0.75 \mathrm{~V}$ [13]. This result is consistent with the fact that under these conditions $\mathrm{H}$ adatoms are almost completely displaced from the $\mathrm{Rh}(111)$ surface by $\mathrm{CO}$ adsorbates.

Calculations indicate that $\mathrm{CO}$ adsorbed structures implying formyl radicals can be also present on the uncharged $\mathrm{Rh}$ surface. This type of adsorbate can be detected through the $\mathrm{CO}$ vibrational frequency shift for $\mathrm{H}_{2} \mathrm{O}$ co-adsorption [9]. However, it is rather unlikely that adsorbed formyl radicals contribute to the voltammetric electro-oxidation of $\mathrm{CO}$ on $\mathrm{Rh}(111)$ because these adsorbed species are unstable at the potential at which they should be detected. The latter lies within the hydrogen electrode reaction potential range.

The voltammetric electro-oxidation of $\mathrm{CO}$ adsorbates on both $\mathrm{Rh}(111)$ and $\mathrm{Pt}$ (111) [13-16,25-29] takes place at a potential sufficiently positive to allow the kinetics of the process to be assigned principally to an interconversion of $\mathrm{CO}$ adsorbates by shifting the adsorbed $\mathrm{CO}$ species to on-top Rh surface sites. According to the MO calculations the multiplicity of electro-oxidation peaks can be related to the number of adsorbed $\mathrm{CO}$ molecules which are involved in cooperative interactions producing definite stable adsorbate ensembles on $\mathrm{Rh}(111)$ at certain well-defined potential ranges. Then, the number of $\mathrm{CO}$ molecules in the adsorbate ensemble determines the stability of the entire adsorbate system and, accordingly, the threshold potential for the $\mathrm{CO}$ adsorbate oxidative electrodesorption.

\section{ACKNOWLEDGEMENT}

The present work was supported by the Consejo Nacional de Investigaciones Científicas y Técnicas and the Comisión de Investigaciones Científicas de la Pcia. de Buenos Aires.

\section{REFERENCES}

1 E. Kölz, H. Neff and K. Müller, J. Electroanal. Chem., 215 (1986) 33.

2 E. Yeager, Surf. Sci., 101 (1980) 1.

3 D. Scherson, B. Yao, E. Yeager, J. Eldridge, M. Kordesch and R. Hoffmann, J. Electroanal. Chem., 150 (1986) 535.

4 R. Kötz, J. Grobecht, S. Stucki and R. Pixley, Electrochim. Acta, 31 (1986) 169.

5 W. Hansen, D. Kolb, D. Rath and R. Wille, J. Electroanal. Chem., 110 (1980) 369.

6 D. Rath and D. Kolb, Surf. Sci., 109 (1981) 641.

7 F. Wagner and T. Moylan, Surf. Sci., 206 (1988) 187. 
8 F. Wagner and T. Moylan, Surf. Sci., 182 (1987) 125.

9 F. Wagner, T. Moylan and S. Schimieg, Surf. Sci., 195 (1988) 403.

10 S. Bilmes, M.C. Giordano and A. Arvía, J. Electroanal. Chem., 2215 (1987) 183.

11 S. Bilmes, M.C. Giordano and A. Arvía, Canadian J. Chem., 66 (1988) 2259.

12 G. Estiú, S. Maluendes, E. Castro and A. Arvía, J. Electroanal. Chem., 283 (1990) 303.

13 S. Bilmes, N. Tacconi and A. Arvía. J. Electroanal. Chem., 143 (1983) 179.

14 P. Paredes Olivera, G. Estiú, E. Castro and A. Arvía, J. Mol. Struct. (Theochem), submitted.

15 B. Beden, A. Bewick, K. Kunimatsu and C. Lamy, J. Electroanal. Chem., 142 (1982) 345.

16 K. Kunimatsu, R.O. Lezna and M. Enyo, J. Electroanal. Chem., 258 (1989) 115.

17 A. Anderson, J. Chem. Phys., 62 (1975) 1187.

18 A. Anderson, R. Grimes and S. Hong, J. Phys. Chem., 91 (1987) 4242.

19 S. Holloway and J.K. Noskov, J. Electroanal. Chem., 161 (1984) 193.

20 D. Kolb, D. Rath, R. Wille and W. Hansen, Ber. Bunsenges Phys. Chem., 87 (1983) 1108.

21 S. Mehandru and A. Anderson, J. Phys. Chem., 93 (1989) 2044.

22 W. Boeck and D. Kolb, Surf. Sci., 118 (1982) 613.

23 S. Ishi, Y. Ohno and B. Viswanathan, Surf. Sci., 161 (1985) 349.

24 A. Anderson, Surf. Sci., 105 (1981) 159.

25 J. Léger, B. Beden, C. Lamy and S. Bilmes, J. Electroanal. Chem., 170 (1984) 305.

26 B. Beden, S. Bilmes, C. Lamy and J. Léger, J. Electroanal. Chem., 149 (1983) 295.

27 S. Bilmes and A. Arvia, J. Electroanal. Chem., 198 (1986) 137.

28 F. Hahn, B. Beden and C. Lamy, J. Electroanal. Chem., 204 (1986) 315.

29 S. Bilmes, Ph.D. thesis, University of Buenos Aires, 1982.

30 G. Padyukova, A. Fasman and I. Khizhlinyak, Electrokhimiya, 4 (1968) 194.

31 P. Thiel, E. Williams, J. Yates and W. Weinberg, Surf. Sci., 84 (1979) 54.

32 L. Dubois and G. Somorjai, Surf. Sci., 91 (1980) 514.

33 J. Kjöll, T. Ala-Nissila and S. Ying, Surf. Sci., 214 (1989) 448. 